\title{
A brief compendium of water entry results derived from laboratory tests of various types of wall assemblies
}

\author{
Michael A. Lacasse ${ }^{1 *}$, Nathan Van Den Bossche ${ }^{2}$, Stephanie Van Linden ${ }^{2}$ and Travis $V$. \\ Moore $^{1}$ \\ ${ }^{1}$ National Research Council Canada, Construction Research Centre, \\ Facade Systems \& Products Group, 1200 Montreal Rd., Bldg. M24, Ottawa, ON, K1A 0R6, Canada \\ ${ }^{2}$ Department of Architecture and Urban Planning, Faculty of Engineering and Architecture, \\ Ghent University, Jozef Plateaustraat 22, 9000, Gent Belgium
}

\begin{abstract}
There is an increase in the use of hygrothermal models to complete the performance evaluation of walls assemblies, either in respect to design of new assembles or the retrofit of existing wall assemblies. To this end there are guides available in which is provided information on moisture loads to wall assemblies. This includes, for example, Criteria for Moisture-Control Design Analysis in Buildings given in ASHRAE 160, Assessment of moisture transfer by numerical simulation provided in EN 15026, and NRC's "Guidelines for Design for Durability of the Building Envelope". The designer of a new assembly or evaluator of an existing wall is tasked with having to determine what moisture loads to apply to the wall and where to apply this load within the assembly. Typically there is little or no information that is readily available regarding moisture loads to walls and thus the suggested hourly moisture load, as given in ASHRAE 160 , is $1 \%$ by weight of the total driving rain load to the wall (i.e. $\mathrm{kg} / \mathrm{m}^{2}$ hr). In this paper, a brief compendium of water entry test results derived from laboratory tests of various types of wall assemblies is provided from which estimates of moisture loads to different types of wall can be developed. Water entry test results are given of wood frame walls typically used in housing, but also metal-glass curtain walls and other commercial wall assemblies, where possible, in terms of driving loads to the wall.
\end{abstract}

\section{Introduction}

There is an increase in the use of heat air and moisture (HAM) transport models to complete the performance evaluation of wall assemblies, either in respect to design of new assembles or the retrofit of existing wall assemblies. The implications of adequate management of moisture in wall assemblies on the durability, resilience and energy efficiency of walls has been by properly described by Weston [1]. Given the importance of ensuring the moisture performance of wall assemblies to achieve their long-term performance, reliance on HAM models has been increasingly evident in recent years for

\footnotetext{
*Corresponding author: michael.lacasse@nrc.ca
} 
this task. There are numerous examples of the use of HAM models to assess the moisture performance of various types of wall assemblies, too many to cite here; however, fewer examples exist as relate to estimating the service life of wall assemblies.

To this end there are guides available which provide information on moisture loads to wall assemblies. This includes, for example, Criteria for Moisture-Control Design Analysis in Buildings given in ASHRAE 160 [2], Assessment of moisture transfer by numerical simulation provided in EN 15026 [3], and NRC's "Guidelines for Design for Durability of the Building Envelope" [4]. The designer of a new assembly or evaluator of an existing wall is tasked with having to determine what moisture loads to apply to the wall and where to apply this load within the assembly. Typically there is little or no information that is readily available regarding moisture loads to walls. A common method, as given in ASHRAE 160 , is $1 \%$ by weight of the total driving rain load to the wall (i.e. $\mathrm{kg} / \mathrm{m} 2-\mathrm{hr}$ ) applied to the exterior surface of the sheathing membrane/water resistive barrier. This load is applied agnostic of wall type or construction details (or potential defects) and details are not necessarily provided as to which instances this $1 \%$ may be conservative or an underestimate. Considering the multitude of cladding types that exist in building stock (i.e. Masonry stone and brick structures and masonry veneer wall assemblies, Concrete panels with rainscreen joints, Metal-glass or metal-panel curtain walls, ETICS (Exterior Thermal insulation composite system), EIFS (Exterior insulated finish system), Wood and hardboard siding painted cladding, and Vinyl (PVC) siding cladding) the relevance of assuming the $1 \%$ value needs to be understood, especially in the case of potential cladding defects. Boardman \& Glass [29] introduced defects through which only wind-driven rain could penetrate, resulting in water entry rates smaller than $1 \%$ of the impinging rain on the exterior surface. Sahal \& Lacasse [28], however, introduced defects through which water entry was recorded caused by gravity alone, resulting in water entry rates much larger than $1 \%$. The significance of using a static $1 \%$ water entry factor irrespective of the severity of the wind driven rain (WDR) event also requires qualification. In general, water infiltration has been recorded without any pressure difference over the wall assembly if openings or deficiencies were present at the exterior surface of the wall assemblies. This implies that the hydrostatic pressure of the runoff film is an important parameter for water infiltration to occur. Therefore, a higher spray rate, i.e. a thicker runoff film, results in a higher water entry rate, as well as a cascading rate on the exterior surface compared to a spraying rate. Measurements conducted by Recatalá, Morales \& Van Den Bossche [23] on ventilated facades showed a parabolic correlation between the spray rate and the infiltration rate. This emphasizes the sensitivity of the applied rain loads on the water entry rate. Also the applied wind pressure difference over the exterior surface of the wall assembly has an impact on the water entry rate. A reduced airtightness of the air barrier causes an increase in the pressure difference over the other layers of the wall assembly, resulting in an increased impact of the wind-driven rain and increased water entry rates. If the cavity behind the rainscreen is not pressure equalized or if no cavity is apparent, the water entry rate will increase for increasing pressure difference. Cyclic test sequences resulted in lower pressure equalization values, especially for wall assemblies with low pressure equalization and small openings in the rainscreen. Water ingress was therefore recorded at lower pressure differences and higher water entry rates were measured.

The information in this paper is primarily focused on presenting a brief compendium of water entry test results derived from laboratory tests of various types of wall assemblies from which estimates of moisture loads through the cladding can be developed. However, examples are also given on how to determine the moisture load to the cladding due to WDR from local climate data. The water entry test results are given primarily of wood frame walls typically used in housing, but also metal-glass curtain walls and other commercial 
wall assemblies, where possible, in terms of driving loads to the wall. Information is also provided as to where in the assembly to apply the moisture load.

Methods to assess moisture loads due to WDR on exterior cladding surfaces - Much information has been published as relates to WDR loads on buildings as may occur around the globe. Lacy and Shellard [5] were perhaps the first to provide such type of information as might be used for modelling. More recent efforts include: Cornick \& Lacasse [6], who provided information as relates to Canada and the US; Giarma and Aravantinos [7] for Greece; Pérez-Bella et al. for Spain [8] and Chile [9]; DomínguezHernández et al. for Brazil [7] and for the UK, Orr \& Viles [11]. These references provide methods by which the WDR load to the cladding can be assessed, given appropriate local climate data information.

As well, considerable information now exists of runoff of water from vertical building surfaces. For example, Blocken \& Carmeliet [12] and Blocken, Derome \& Carmeliet [13] have provided a highly useful review on this topic and have thereafter offered approaches to its implementation in HAM models [14]. The proposed methods offer insight into how moisture loads on the exterior of the cladding can vary, and how to consider effects of runoff in hygrothermal simulations.

\section{Overview of water infiltration of wall assemblies}

What occurs thereafter in respect to wind-driven rain impinging on vertical building surfaces and the risk to water infiltration entirely depends on the nature of the cladding or wall surface, the presence of openings or deficiencies in the wall through which water can enter, and pressure differences across openings. In a porous substrate, such as stone masonry veneer, water is taken up by capillary action and sorption occurs towards the interior of the masonry unit and inwards of the cladding. Sorption is enhanced at locations between adjacent panels should interstitial spaces be small and capable of sustaining capillary action. Whereas, for example in brick masonry veneer, small cracks exist between the mortar and the brick unit, and water is preferentially taken up in these openings at this interface.

Given that water infiltration in the plane of the exterior cladding is not uncommon, but neither is it considered typical as compared to water entry at through-wall penetrations, information thus ought to as well to be provided for penetrations of walls as they represent point sources of infiltration water that can likewise been simulated. Thus, for each cladding type there are associated details regarding the installation of through-wall penetrations such as windows (i.e. fenestration products), ventilation ducts and electrical outlets. Additionally, consideration should also be given to water infiltration at joints in the cladding. The following information is provided as a summarised overview on water infiltration of different wall assembly types, as well as infiltration of fenestration products, ventilation ducts, and joints; more detailed information can be found in the references.

An overview of water infiltration rates of wall assemblies is given in Table 1 . The water infiltration is described in terms of different wall types as well as different through-wall penetrations, such as windows, pipes and ventilation ducts, and the infiltration of water through joints of walls. Where possible, information has been given on rates of water infiltration at specific pressure differences; when not available information has been provided on the range of infiltration rates observed from test.

Water infiltration of "generic" wall assemblies - Studies of water infiltration of "generic" walls have been undertaken through the process of developing watertightness test standards. In this regard work by Lacasse et al. [15] undertook infiltration tests of water entry through deficiencies located at the top of a ventilation duct, an electrical outlet and at adjacent lower corners of a vinyl window incorporated in a prototype wood-frame cavity 
wall. This prototype wall was fabricated in three layers of clear acrylic plate such that it included a cladding and rainscreen, a barrier acting as second line of defence, and an air barrier. 
Table 1. Overview of water infiltration rates of different wall assemblies tested in laboratory conditions

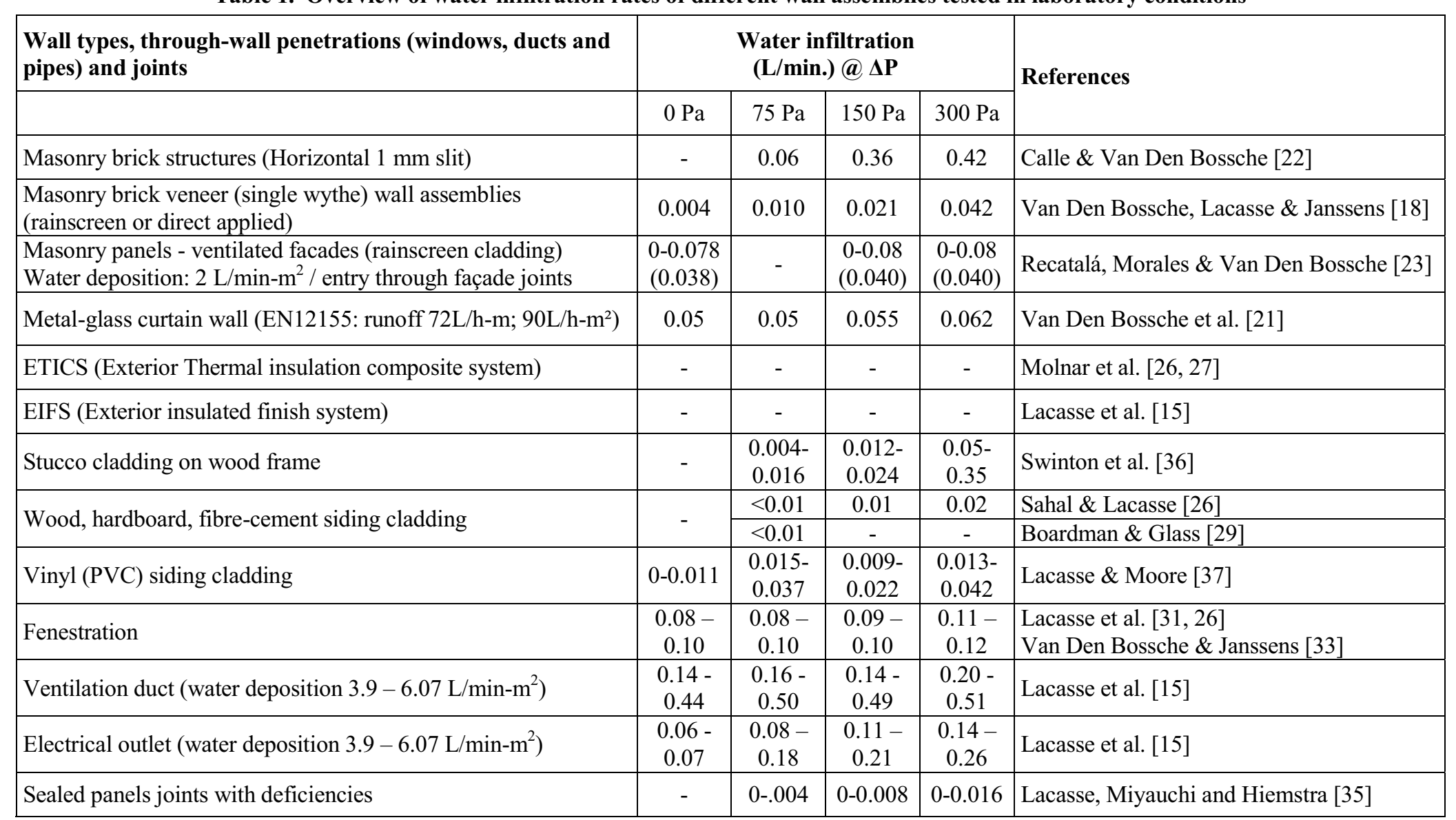


The deficiencies located in the cladding and elsewhere in the assembly were subjected to simulated precipitation (water spray) concurrent with either static or dynamic pressure differentials across the assembly. The amount of water entering deficiencies of known size at specific locations on a wall assembly was quantified given simulated precipitation (water spray) rates, wind pressure differentials and air leakage characteristics of the assembly. Measured rates of water entry through both the deficiency at the electrical outlet and at the top of the ventilation duct were significant when no pressure was applied, implying that water entry occurred due to gravity. Water entry varied linearly as a function of the simulated rate of precipitation and increased in proportion to the static pressure difference. Dynamic pressure fluctuations resulted in the same water entry rates as those obtained under static pressure conditions.

Van Den Bossche et al. [16], completed similar work but at a reduced scale in which infiltration rates were quantified for specific circular opening sizes considering various static pressure differences and water deposition rates on a vertical surface. Water started flowing through the 1 and $4 \mathrm{~mm}$ openings at a pressure difference of $600 \mathrm{~Pa}$. Water infiltration was however already recorded without any additional pressure difference for the $8 \mathrm{~mm}$ openings. For increasing pressure, the water entry rate through the $8 \mathrm{~mm}$ openings increased. Significantly larger infiltration rates were measured for leaky air barriers and dynamic pressure fluctuations compared to tight barriers. With a tight barrier the pressure difference over the rainscreen equals almost $0 \mathrm{~Pa}$, reducing the water entry rate. Also the larger openings result in better pressure equalization and lower pressure differences over the rainscreen.

Water infiltration of masonry wall assemblies - Grimm [17] provides a useful starting point for acquiring information related to water permeance of masonry walls whereas Van Den Bossche, Lacasse \& Janssens [18] offer a more recent and highly relevant overview of the watertightness of masonry walls complete with ranges of water infiltration rates. The literature review of laboratory experiments showed a wide range of measured values for water infiltration through brick veneer walls (between $0 \%$ and $20 \%$ ). The results of some field tests however, showed water infiltration rates between $0 \%$ and $3.4 \%$.

The watertightness of masonry cavity walls having blown-in insulation is described by Van Goethem, Van Den Bossche \& Janssen [19]. In general, the water infiltration rate increases for an increasing pressure difference. All test samples, except the samples filled with PUR-foam already showed water infiltration without any pressure difference. This indicates that the water spray rate and the occurrence of runoff are the most significant parameters for water infiltration. The masonry cavity filled with PUR-foam almost eliminated water ingress. The cavity filled with EPS-beads, however, showed a high rate of water ingress.

The infiltration of rain in historic brickwork is less well understood however, Calle \& Van Den Bossche provide some information on this topic [20].

Water infiltration of curtain-walls \& ventilated facades - Few studies have been published on the water infiltration performance of curtain wall systems and typical failure phenomena; the work described by Van den Bossche et al. [21] helps fill this void. Several cases studies were reviewed and the results indicate that curtain walls systems seem susceptible to water ingress. Results from their experimental work on a curtain wall system are presented and analysed in terms of the amount of water infiltrated into the cavity as measured during both static and cyclic water infiltration tests. The amount of water ingress did not show any correlation with the overall pressure differential over the system, indicating that the main force causing water to infiltrate past the first barrier is the hydrostatic pressure exerted by the runoff film. Cyclic test sequences resulted in water ingress to the interior at lower pressure differences and at greater rates as compared those obtained under static test sequences. Cyclic pressure fluctuations resulted in lower pressure 
equalization values, resulting in water ingress into the interior at lower pressure differences as compared to static pressure differences.

In respect to ventilated facades, a good many problems occur in rainscreen walls having natural stone coverings [22]. In this respect, Recatalá, Morales \& Van Den Bossche [23] provide useful information on quantities of water that can percolate through open joints. The laboratory test results showed that $49.7 \%$ of the sprayed water splashes back, $22.5 \%$ created a runoff film along the exterior surface, $27.3 \%$ infiltrated into the air cavity, and $0.54 \%$ reached the exterior surface of the thermal insulation layer. For a high airtightness level of the air barrier, the applied pressure differences did not have any impact on the measured water infiltration rates. However, for a leaky air barrier, the pressure moderation was not as rapid as for the tight air barrier. The correlation obtained between the spray rate and the infiltration rate fitted to a parabolic function.

Water infiltration of ETICS \& EIFS wall assemblies - Several studies have been completed on determining moisture performance of ETICS [e.g. 24, 25] and EIFS wall assemblies. Fewer studies have provided information related to water infiltration, although work by Molnar et al. provides some qualitative information [26, 27]. In all tests, water infiltrated through an artificial crack in the render and resulted in discharge of water through: the render-insulation interface, at joints between the insulation sheets, at mechanical fasteners and at localized areas on the back side of the insulation sheets. The combined effect of a water film running down along the exterior surface and the pressure created by the wind caused water to infiltrate through the cracks.

For EIFS walls, information related to water infiltration can be found in Lacasse et al. [15]. Certain walls did not exhibit any signs of water penetration into the stud cavity due to drainage mechanisms installed in the walls, such as, vertical grooves in the adhesive layer or grooves in the EPS. The wall without any drainage mechanism appeared to be the most affected by water penetration in the bulk of the wall cladding. Most of the infiltrating water was observed beneath windows.

Water infiltration of wood, hardboard and vinyl siding - Sahal \& Lacasse [28] report on the experimental assessment of water infiltration and entry rates into hardboard siding-clad wall assemblies typical in North American construction. The water infiltration was characterised in respect to rates of entry for selected water deposition rates on the wall surface and air pressure differential across the wall. Water entry through the deficiencies occurred even when there was no pressure difference across the specimen. Increase in water entry rate was dependent on the increase in spray rate. Cascading water rates on the cladding surface resulted in higher rates of water entry. The presence of the water film in the vicinity of the deficiency acted as a barrier, increasing the driving pressure across the cladding. The driving pressure was further increased when the amount of water deposition increased on the cladding.

In a similar fashion, Boardman \& Glass [29] describe an apparatus used to deliver realistic wind-driven rain loads at two wind (pressure) conditions and a range of rain intensities onto an exposed rainscreen lap-siding wall. Results are presented as a function of the intensity of water spray, the location of deposition on the wall, and wind speed. Three defects were introduced by sliding a wedge up between the lap siding. Rain intrusion was not measured past well-installed lap siding. Wind-driven rain with a significant wind speed was required to see rain intrusion through the defects. Therefore, much smaller water entry rates were measured than the rates measures by Sahal and Lacasse [28]. Results from either of these studies are markedly different given the defects through which water infiltrated and the simulated loads to which the walls were subjected; in some instances entry rates reported by Boardman \& Glass [29] are 1/1000 that of Sahal \& Lacasse [28]. From the results Boardman \& Glass [29] suggest that modelling using a 1\% intrusion rate may be too high. 
Water infiltration at windows and fenestration products - A number of studies have been completed regarding water infiltration at windows, including those completed by Lacasse et al. [15], in which water entry rates of deficient windows installed in a number of different typical wood-frame wall assembly types were characterised in respect to rates of entry, air pressure differential across the wall, and the wall air leakage rate. Thereafter, a series of studies were completed of water infiltration at window penetrations in respect to different window installation methods typical of North American construction for various wood-frame wall assemblies; these have been published in Lacasse et al. [30, 31]. The results indicate that water enters even when no pressure is applied. The water collection rates at the windowsill increased with: increasing spray rate, increasing pressure difference, and reduced airtightness of the air barrier.

Similar work was carried out by Lopez, Masters \& Bolton [32], however results were reported in a qualitative manner (the time to leakage under set conditions was reported) compared to quantitative assessments provided in Lacasse et al [15].

Results of water infiltration of windows following European building practice and test methods can be found in the work of Van Den Bossche \& Janssens [33]. Results of air and watertightness tests of different windows (vinyl, aluminum, and wood frame) are provided. Results of water infiltration are given in respect to the range of pressures at which infiltration was observed for the different windows investigated.

Water infiltration at ventilation ducts, pipes and electrical outlets Information regarding water infiltration at ventilation ducts and electrical outlets incorporated in various types of wood-frame wall assemblies typical of North American construction practice can be found in Lacasse et al. [15].

Water infiltration at wall joints - Few studies have been published regarding water infiltration at joints in building structures hence this topic has, to date, been insufficiently covered. Nonetheless work has been published by Sasaki and Platts [34] regarding the water entry through vertical wood batten joints between plywood insulated panels. In their study, testing was conducted using a wetting rate of $0.85 \mathrm{~L} / \mathrm{min}-\mathrm{m}^{2}\left(51 \mathrm{~mm} / \mathrm{hr}^{2} \mathrm{~m}^{2}\right)$ at a pressure difference of $137 \mathrm{~Pa}$ over a 15 minute period; only the presence of leakage across the joint was noted. Lacasse et al. [35] in completing hygrothermal studies of wall assemblies focused on determining the effects of failed sealed joints by incorporating deficiencies (openings) along joints as locations for water entry in the wall. For example, if the crack length in a joint of an actual building is known or verified from a field inspection, an estimate of the rate of water leakage can be calculated by using the information given in Lacasse et al. [35], provided information is also given on the expected climate loads acting on the façade.

\section{Moisture source for hygrothermal simulations}

Determining the rates of water entry for each infiltration case described in the previous section, and summarized in Table 1, as a function of pressure, enables one to determine water entry rates for hygrothermal simulations. However, the knowledge of appropriate rates of water entry for a given infiltration condition or wall assembly type is not the only information required for completing hygrothermal simulations, one needs to determine upon which surface the wall assembly to the water infiltration as a moisture source. When using the results of water entry tests as a moisture source input to hygrothermal simulations, it is important to understand the specific approach that was adopted in the test configuration. The approach used in water entry tests should match that which is being simulated, i.e. WDR loads, airtightness level, pressure equalization rate, cavity width, capillary break etc., and should be as close as possible to that which is being assessed in the simulations. Additionally, any discrepancies or assumptions which exist between the test 
values used to determine the moisture source for the simulations, and the configuration being simulated, should be noted.

As stated previously, ASHRAE S160 recommends that the water entry is placed on the exterior surface of the sheathing membrane/water resistive barrier, assuming that the infiltration makes it through the cladding and to the surface of the WRB. This may be considered a conservative approach, especially in the case in which a cladding system incorporates a capillary break. The majority of water infiltration is then most likely to remain on the interior surface of the cladding, although some water entry could be assumed to bridge the capillary break through cladding penetrations such as vent pipes and electrical outlets. Although in a common sense approach this is the case, it is difficult to determine the division of water entry in these cases. From a conservative standpoint, it is likely best to assume the entire moisture source occurs on the exterior surface of the sheathing board, as per ASHRAE S160. However further research is required to recommend any potential division of moisture source between surfaces. Regardless, any assumptions on the division of water entry between surfaces should be clearly stated in any hygrothermal simulation work.

The authors are indebted to the National Research Council Canada, Construction Research Centre, Ottawa, and as well the Department of Architecture and Urban Planning of Ghent University (BE), for having supported the work described in this paper.

\section{References}

1. T. Weston, "The Implications of Durability, Resilience and Energy Efficiency on the Advancement of Water Management in Wall Assemblies," Advances in C. Eng. Matls., Vol. 7(1); pp. 316-339 (2018) https://doi.org/10.1520/ACEM20170109

2. ASHRAE 160-2016, Criteria for Moisture-Control Design Analysis in Buildings; 20 p.

3. BS EN 15026:2007, Hygrothermal performance of building components and building elements. Assessment of moisture transfer by numerical simulation; $28 \mathrm{p}$.

4. Lacasse, M. A., Ge, H.; Hegel, M.; Jutras, R.; Laouadi, A.; Sturgeon, G., Wells, J., Guideline on design for durability of building envelopes, Technical Report CRBCPI-Y2R19; Construction, National Research Council Canada (2018), 35 p.; DOI: $10.4224 / 23003983$

5. R. E. Lacy and H. C. Shellard (1962), An Index of Driving Rain, The Meteorological Magazine, 91(1080), July 1962, pp. 177-184:

6. S. Cornick and M. Lacasse, "A Review of Climate Loads Relevant to Assessing the Watertightness Performance of Walls, Windows, and Wall-Window Interfaces," J. ASTM Intl., Vol. 2(10), pp. 1-15; (2005); DOI: 10.1520/JAI12505

7. C. Giarma, D. Aravantinos (2014), On building components' exposure to driving rain in Greece, J. Wind Eng. Ind. Aerodyn. 125; pp. 133-145; (2014)

8. J. M. Pérez-Bella, J. Domínguez-Hernández, J. J. del Coz-Díaz, E. Cano-Suñén, B. Rodríguez-Soria, Optimised method for estimating directional driving rain from synoptic observation data, J. Wind Eng. Ind. Aerodyn.113; pp. 1-11; (2013)

9. J. M. Pérez-Bella, J. Domínguez-Hernández, E. Cano-Suñén, J. J. del Coz-Díaz, M. Alonso-Martínez, Global analysis of building façade exposure to water penetration in Chile, Building and Environment, Vol. 70 (2013) pp. 284-297

10. J. Domínguez-Hernández, J.M. Pérez-Bella, M. Alonso-Martínez, E. Cano-Suñén \& J.J. del Coz-Díaz, Assessment of water penetration risk in building facades throughout Brazil, Building Research \& Information, 45(5); 492-507 (2017); 
11. S. A. Orr, H. Viles, Characterisation of building exposure to wind-driven rain in the UK and evaluation of current standards, J. Wind Eng. Ind. Aerodyn. 180; 88-97 (2018)

12. Blocken \& J. Carmeliet, A simplified numerical model for rainwater runoff on building facades: possibilities and limitations. Bldg. \& Environ. 53 (2012):59-73

13. B. Blocken, D. Derome, J. Carmeliet, Rainwater runoff from building facades: A review, Bldg. \& Environ.60 (2013): 339-361B.

14. T. Van den Brande, B. Blocken \& S. Roels, Rain water runoff from porous building facades: Implementation \& application of a first-order runoff model coupled to a HAM model, Bldg. \& Environ. 64 (2013): 177-186

15. Lacasse, M.A.; O’Connor, T.J.; Nunes, S.; Beaulieu, P., Report from Task 6 of MEWS Project - Experimental Assessment of Water Penetration and Entry into Wood-Frame Wall Specimens - Final Report, Research report IRC-RR-133, Institute for Research in Construction, National Research Council Canada, Ottawa, February 2003, 308 p

16. N. Van Den Bossche, M. Lacasse, T. Moore and A. Janssens, Water infiltration through openings in a vertical plane under static boundary conditions, Proc., 5th Intl. Building Physics Conference. (2012) pp. 457-463

17. C.T. Grimm, Water Permeance of Masonry Walls: A Review of the Literature; in: Borchelt JG, Ed., Masonry: Materials, Properties, and Performance; ASTM STP 778; ASTM International, (1982); DOI: 10.1520/STP30122S

18. N. Van Den Bossche, M. A. Lacasse and A. Janssens, Watertightness of masonry walls: an overview, $12^{\text {th }}$ International Conference on the Durability of Building Materials and Components (12DBMC), Porto, PT, April 12-15, 2011, pp. 1-8

19. S. Van Goethem, N. Van Den Bossche, A. Janssen, Watertightness Assessment of Blownin Retrofit Cavity Wall Insulation, Energy Procedia, Vol. 78 (2015) pp. 883-888

20. K. Calle, N. Van Den Bossche (2017), Towards understanding rain infiltration in historic brickwork, Energy Procedia 132; 676-681 (2017)

21. N. Van Den Bossche, S. Van Goethem, S. Scharlaken, S. Sulmon, A. Janssens, Watertightness and water management of curtain walls, $1^{\text {st }}$ Intl. Symposium on Building Pathology (ISBP-2015), 24-27 March 2015, Univ. of Porto, Porto, PT; pp. 431-438.

22. J. Gutiérrez, Á. Mas, E. Gil, V. Galvañ, Clay-related damage in rainscreen walls built with natural stone coverings, Constr. \& Bldg. Matls., Vol. 29, (2012) pp. 357-367

23. M. A. Recatalá, S. G. Morales \& N. Van Den Bossche, Experimental assessment of rainwater management of a ventilated façade. J. of Building Phys., 2018, Vol. 42(1) 38-67

24. S. Ilomets, T. Kalamees, J. Lahdensivu, P. Klõšeiko, Impact of ETICS on Corrosion Propagation of Concrete Façade, Energy Procedia, Vol. 96; pp. 67-76; (2016)

25. Barreira E., de Freitas V.P. (2016) Experimental Studies on Hygrothermal Behaviour of ETICS. In: External Thermal Insulation Composite Systems (ETICS). Springer Briefs in Applied Sciences and Technology. Springer, Cham

26. Molnar, M., Jönsson, J., Sandin, K., \& Capener, C-M. (2013). Energieffektivisering av miljonprogrammets flerbostadshus genom beständiga tilläggsisoleringssystem. Report TVBK-3064, Lund University, Division of Structural Engineering, Lund, Sweden; 102p.

27. Molnar, M., Jönsson, J. and Rosenkvist P-O., Development of experimental methods to evaluate infiltration of WDR into external thermal insulation composite systems (ETICS) in : XIV DBMC $-14^{\text {th }}$ International Conference on Durability of Building Materials and Components, 29-31 May 2017, Ghent University, Belgium; pp. 29-30

28. Sahal, N.; Lacasse, M. A., Water entry function of a hardboard siding-clad wood stud wall, Building \& Environ. 40(11) (2005), pp. 1479-1491 
29. C.R. Boardman and S.V. Glass, Investigating Wind-Driven Rain Intrusion In Walls with the CARWASh, Thermal Performance of the Exterior Envelopes of Whole Buildings XII, Intl. Conf., ASHRAE, 11p.; (2013)

30. M. A. Lacasse, M. Manning, M. Rousseau, S. M. Cornick, S. Plescia, M. Nicholls, S. Nunes, Results on Assessing the Effectiveness of Wall-Window Interface Details to Manage Rainwater; $11^{\text {th }}$ Canadian Conference on Building Science \& Technol., Banff, AB, 2007, Institute for Research in Construction, National Research Council Canada.

31. Lacasse, M. A.; Manning, M. M.; Ganapathy, G.; Rousseau, M. Z.; Cornick, S. M.; Bibee, D.; Shuler, D.; Hoffee, A. (2009), Assessing the effectiveness of wall-window interface details to manage rainwater - selected results from window installation to a wall, sheathed in extruded polystyrene, Journal of ASTM International, 6(9): pp. 1-43,

32. C. Lopez, F. J. Masters \& S. Bolton, Water penetration resistance of residential window \& walls subjected to steady \& unsteady wind loading, Bldg. \& Environ. 46 (2011): 1329-1342

33. N. Van Den Bossche \& A. Janssens, Airtightness \& watertightness of window frames: Comparison of performance \& requirements, Bldg. \& Environ. 110 (2016) 129-139

34. J. R. Sasaki, and R. E. Platts, Tests on vertical joints for a wood-panel wall system, Rain leakage tests on vertical through -joints, DBR/NRC Research Paper No. 337, Div. of Building Res., National Research Council Canada, Ottawa, Oct., 1968; 4 p.

35. M. A. Lacasse, H. Miyauchi and J. Hiemstra, (2009), "Water Penetration of Cladding Components - Results from Laboratory Tests on Simulated Sealed Vertical \& Horizontal Joints of Wall Cladding," J. ASTM Intl., Vol. 6(6), pp. 1-21; (2009); DOI: 10.1520/JAI102048. ISSN 1546-962X

36. Swinton, M., Lacasse, M. A., Armstrong, M., Saber, H., Mukhopadhyaya, P., Lohman, F., Maref, W., Kumaran, K., Ganapathy, G., Nicholls, M., Abdulghani, K. (2010), Moisture Management Assessment of the Adhered Stone Cladding System - Final Summary Report, Client Report; B-8145.6; September 1, 2010; Institute for Research in Construction, National Research Council Canada, Ottawa; 108 p.

37. M. A. Lacasse and T. V. Moore, 2018, Approach to incorporating water entry and water loads to wall assemblies when completing hygrothermal modelling, ASTM Symposium on Building Science and the Physics of Building Enclosure Performance - Part 1, 21 October, Washington DC, ASTM International, West Conshohocken, PA; 30 p. 